DOI 10.37882/2223-2974.2021.05-2.12

\title{
СИСТЕМАТИЗАЦИЯ ЭФФЕКТОВ ИНТЕГРАЦИИ БЛОКЧЕЙН ТЕХНОЛОГИЙ В ХОЗЯЙСТВЕННУЮ СРЕДУ: ДИАЛЕКТИЧЕСКИЙ ПОДХОД'
}

\section{SYSTEMATIZATION OF THE EFFECTS OF INTEGRATION OF BLOCKCHAIN TECHNOLOGIES INTO THE BUSINESS ENVIRONMENT: A DIALECTIC APPROACH \\ M. Safiullin \\ R. Burganov L. Elshin}

Summary: The subject of the research is the economic relations of economic agents regarding the use of blockchain technologies in economic activity and the formation of new forms of building business models. The authors consider in detail the opportunities and risks for the development of the financial and real sectors of the economy within the framework of diffusion and blockchain technologies in the context of key areas of their impact: asset verification, accounting and maintenance of a database of transactional transactions, data confidentiality and transaction costs (operating costs). Particular attention is paid to the study of risks and limitations in the process of using distributed data storage technologies in the framework of dialectical analysis to study the question posed.

The study is an attempt to systematize the effects considered for the economy as a result of the penetration of blockchain technologies into the socioeconomic environment, grouping them according to general features, in terms of the direction of impact. The main conclusion of the study is to substantiate the need to develop methodological approaches to a formalized assessment of risks and opportunities for the national economic system as part of the integration of the studied technologies into the ecological environment. The novelty of the research lies in the identification and systematization of positive and negative externalities for the national economy, caused by the spread of the studied technologies and their integration into the system of economic relations.

Keywords: blockchain technologies, opportunities, risks, systematization of effects, economic growth, economic environment, externalities, national economy, real sector of the economy, financial sector of the economy, blockchain networks.

\section{Введение}

локчейн-технологии все еще, несмотря на набирающий уровень их популяризации в научно-экспертном сообществе, являются новыми и активно раз-
Сафиуллин Марат Рашитович

Д.э.н., профрессор, ФГАОУ ВО "Казанский (Приволжский) федеральный университет"

Marat.Safiullin@tatar.ru

Бурганов Рафис Тимерханович

К.э.н., дочент, ФГБОУ ВО «Казанский государственный архитектурно-строительный университет»

c.p@tatar.ru

Ельшин Леонид Алексеевич

Д.э.н., ФГАОУ ВО "КазанскИй (Приволжский) федеральный

университет"

Leonid.Elshin@tatar.ru

Аннотация: Предметом исследования являются экономические отношения экономических агентов по поводу использования в хозяйственной деятельности блокчейн технологий и формирования новых форм построения бизнес-моделей. Авторы подробно рассматривают возможности и риски для развития финансового и реального секторов экономики в рамках диффузии блокчейн технологий в разрезе ключевых направлений их воздействия: проверка активов, учет и ведение базы данных трансакционных сделок, конфиденциальность данных и затраты по сделке (операционные издержки). Особое внимание уделяется исследованию рисков и ограничений в процессе использования технологий распределенного хранения данных в рамках диалектического анализа к исследованию поставленного вопроса.

Исследование является попыткой систематизировать рассматриваемые для экономики эффекты в результате проникновения в социоэкономическую среду блокчейн технологий, сгруппировав их по общим признакам, с точки зрения направления воздействия. Основным выводом проведенного исследования является обоснование необходимости выработки методических подходов к формализованной оценке рисков и возможностей для национальной экономической системы в рамках интеграции исследуемых технологий в экосреду. Новизна исследования заключается в идентификации и систематизации положительных и отрицательных экстерналий для национальной экономики, вызванных в процессе распространения изучаемых технологий и их интеграции в систему экономических отношений.

Ключевые слова: блокчейн технологии, возможности, риски, систематизация эффектов, экономический рост, хозяйственная среда, экстерналии, национальная экономика, реальный сектор экономики, финансовый сектор экономики, блокчейн сети.

вивающимися, что ограничивает понимание того, какие возможности и риски они могут сформировать для развития финансовой системы и национальной экономики в целом. В этой связи, в условиях неопределенности, регуляторы достаточно скептически смотрят на возмож-

Исследование выполнено за счет гранта Российского научного фонда (проект №19-18-00202). 
ность их широкого применения в системе хозяйственных отношений.

Опасения регуляторов вызваны целым рядом причин, главными из которых являются децентрализованный характер финансовых транзакций с возможностью их обезличивания, что генерирует риски безконтрольного обращения финансовых ресурсов. Кроме того, проблема заключается и в том, что сами финансовые институты (банки, брокеры, клиринговые дома и т.п.) не понимают в полной мере как работают криптовалюты, блокчейн-системы и, соответственно, нет понимания того, каким образом будут формироваться транзакции в рамках рассматриваемых технологий, в каком количестве и к каким последствиям это может привести [1-4].

Аналогичный тезис справедлив и для предприятий реального сектора экономики, которые в условиях информационного фона об усиливающихся процессах проникновения блокчейн технологий в систему операционных процессов (к примеру заявление Центрального банка Российской Федерации о перспективах внедрения цифрового рубля и блокчейн технологий в платежную систему [5]), не имеют полного представления о возможностях, открывающихся для них и рисках, генерирующихся в этой связи.

Несомненно, в научной и экспертной литературе сегодня можно встретить весьма значительное количество работ, раскрывающих поставленные здесь вопросы. Однако все они, зачастую, носят, как правило, в определенной степени фрагментарный характер, выраженный, в первую очередь, в идентификации возможных эффектов и последствий для хозяйствующих субъектов через призму базовых, укрупненных экстерналий. Кроме того, не достаточно проработаны и вопросы их систематизации, с точки зрения направлений воздействия как на конкретные сектора экономики, так и на всю экономическую систему в целом.

На наш взгляд, обозначенная проблема относится к классу методических и требует реализации специальных мероприятий, направленных на поиск механизмов, обеспечивающих ее решение. К ним, необходимо отнести не только идентификацию и обоснование направлений воздействия, но и конкретизацию возможных последствий и их систематизацию.

\section{Методы}

Неизбежность блокчейнизации национальной и глобальной экономических систем обусловлена, в первую очередь, тем, что она позволит в большей степени автоматизировать процессы операционного управления и механизмы проведения новых финансовых криптотранзакций, что сформирует предпосылки роста экономиче- ской эффективности хозяйствующих субъектов за счет высвобождения временных, материальных и человеческих ресурсов [6].

Решение вопроса о значимости блокчейн технологий и их влияния на параметры и устойчивость национальной экономики лежит, в первую очередь, в плоскости идентификации и определения ключевых эффектов, порождаемых их использованием в хозяйственной деятельности экономических агентов.

Совершенно очевидно, что блокчейн технологии имеют первоочередное значение в сфере реализации финансовых операций в части:

- снижения посреднических комиссий за их проведение;

- социализации каналов доступа к финансовым рынкам (расширение доступа экономических агентов к фондовым торговым площадкам);

- расширения возможностей повышения ликвидности капитала кредитных организаций за счет повышения эффективности операционных процессов (что обеспечивает снижение операционных и кредитных рисков);

- расширениявозможностейдляповышенияфинансовой устойчивости бизнес-сообщества за счет дополнительного прироста оборотных активов, как результат локализации на финансовых рынках комиссионных доходов за финансовые транзакции; и т.п.

Кроме того, несомненно, этим перечнем положительных экстерналий позитивные для экономики эффекты не ограничиваются. Их идентификация должна лежать в русле систематизации генерирующихся экстерналий, причем не зависимо от того, какого они типа: положительные или отрицательные.

\section{Результаты и обсужление}

Опираясь на изложенный подход к исследованию, формирующиеся, в рамках интеграции блокчейн технологий в хозяйственную среду, возможности и риски для развития финансового и реального секторов экономики, представлены ниже в разрезе ключевых направлений, объективно представленных в работе А. Тиллоби. [7].

\section{1) Проверка активов}

1.1 Блокчейн-сети имеют очень высокий уровень конгруэнтности целей ее участников, что порождает достоверность фиксации новой информации и актуальность данных, характеризующих транзакции в прошлом.

1.2 В отличие от ресурсов Интернета, который стремится представить всеобъемлющую информацию, зачастую характеризующуюся своей не- 
надежностью, неактуальностью, информация, хранящаяся в блокчейн-системах защищена от фальсификации, всегда актуальна и не содержит «мусорные» характеристики изучаемого объекта.

1.3 Применение в системе обмена данными блокчейн-сетей формирует возможность консолидации данных в единый репозитарий, что сокращает потребность в ресурсах, затрачиваемых на сбор и обработку информации, а также формирует основу для получения актуальной и достоверной информации.

1.4 Снижение издержек на судебные споры (ввиду эффекта хронологической отслеживаемости и неизменности данных в блокчейн-системах).

1.5 Важнейшей составляющей, обосновывающей положительные перспективы динамичного развития блокчейн технологий, это возможность создания на их основе «умных» контрактов, которые будут нивелировать риски двусмысленных ситуаций, что приведет к ликвидации спорных отношений между участниками сделки.

1.6 Снижение затрат в результате высвобождения трудовых ресурсов, занятых обработкой и проверкой достоверности данных клиентов.

1.7 Оптимизация дивидентного и налогового планирования компаний на основе проверки активов с точки зрения достоверности их данных и всех сопутствующих атрибутов, сверки записей относительно истории формирования актива.

2) Учет и ведение базы данных трансакционных сделок.

2.1 Применение в банковской деятельности блокчейн технологий будет способствовать «прозрачности» финансовой деятельности за счет строгой регламентации правил работы финансового рынка и его участников и набора запрограммированных блокчейном действий.

2.2 Финансовому сектору экономики целесообразно применять блокчейн технологии, в рамках совершенствования процесса ведения учета данных, в следующих направлениях и сферах операционной деятельности:

- фондовые рынки, где текущий процесс обработки сделок требует медленного и ручного контроля записей реестра владения акциями и иными ценными бумагами;

- рынки кредитования;

- рынки корпоративных облигаций, где технология блокчейн могла бы оцифровать записи в изменении владения и стоимости активов и кодифицировать необходимые расчеты;

- деривативный рынок, где «прозрачность» сделок, история в отношении ранее реализованных операций, транзакций могут су- щественным образом сократить стоимость трансакционных издержек, сократить время на мониторинг и совершение постторговых процессов [8];

- ведение и управление базами данных клиентов в целях создания централизованного репозитария для облегчения задачи контроля достоверности данных.

- в соответствии с подходом [9] блокчейн-технологии крайне эффективны на рынке РЕПО, где в качестве ключевой функции выступают договора обратного выкупа.

\section{3) Конфиденциальность данных.}

3.1 В блокчейн-системах пользователи (участники) могут контролировать уровень своей конфиденциальности, что формирует возможность контроля доступа третьих лиц к идентификации профиля участника сети

3.2 Использование в системе финансовых транзакций блокчейн-сетей способствует полномасштабной реализации проведения процедуры KYC.

4) Затраты по сделке (операционные издержки).

4.1 Технологии блокчейн и построенные на их основе расчетные, платежные платформы существенным образом могут заменить функционал и предназначение системы посредничества в финансовой сфере, что обеспечит трансформацию процессов клиринга, структуру и состав операционных рисков финансовых учреждений, сферу страхования, ведения и учета многоранговых баз данных о финансовых транзакциях и др.

4.2 Блокчейн-технологии формируют новые бизнес решения в сфере учета и контроля финансовых транзакций, сочетающие в себе такие функции, как прозрачность и конфиденциальность. То есть в условиях конфиденциальности проводимые сделки прозрачны.

4.3 Сокращение затрат на международные платежи и торговые расчеты.

4.4 Интеграция в финансовую экосреду блокчейн технологий позволит снизить стоимость транзакций в результате обострения конкурентной среды на рынке обслуживания денежных переводов. Сегодня в платежном секторе есть две транснациональных компании, предоставляющих услуги проведения платежных операций: Visa и MasterCard, формирующие, по сути, дуополию на рынке.

\section{5) Дополнительные возможности.}

5.1 Блокчейн технологи, формирующие основу для проведения криптотранзакций открывают но- 
вые возможности для развития инвестиционных рынков, фактически социализируя процессы инвестиционной активности экономических агентов.

5.2 Технология блокчейн может расширить доступ к рынкам капитала, посредством социализации процесса интеграции экономических агентов в финансовые рынки;

5.3 Технология блокчейн способна обеспечить ускоренную динамику развития экономики, за счет оптимизации расходов и снижения операционных издержек хозяйствующих субъектов.

5.4 Блокчейн технологии позволяют повысить уровень автоматизации операционных процессов организаций, что обеспечивает им рост конкурентоспособности и повышение финансовых результатов.

5.5 Максимально возможный уровень безопасности функционирования блокчейн-систем в контексте несанкционированного доступа (взлома) к данным ее участников.

5.6. Технологии блокчейн могут устранить многие известные и актуальные для настоящего времени проблемы в секторе финансовых услуг - мошеничество, операционные риски, задержки в системе финансовых транзакций и платежей.

5.7 Блокчейн технологии обеспечивают возможность контроля реализуемых финансовых транзакций для регуляторов, в случае если последние интегрированы в открытые блокчейн-сети.

5.8 Использование блокчейн технологий способствует сокращению финансовых операционных издержек, возникающих в рамках нормативного соблюдения требований национальных и международных юрисдикций

5.9 Повышение контроля за финансовым рынком со стороны регуляторов в рамках применения концепции использования открытых блокчейнсистем.

5.10 Участники блокчейн-систем способствуют созданию низкого уровня неопределенности и повышают производительность генерации финансовых транзакций.

5.11 Применение блокчейн-технологий может существенно расширить диапазон услуг в сере финансовых операций. При этом данное расширение будет достигаться, в первую очередь, не за счет повышения уровня автоматизации процессов, а за счет появления новых форматов построения бизнес-моделей.

5.12 Блокчейн технологии являются весьма эффективным инструментом обеспечения новых форм развития бизнеса на основе привлечения инвестиций и формирования новых принципов работы на рынках капитала в виде ICO.
5.13 Использование технологий распределенного хранения данных формирует масштабную возможность глобализации и снятия географических барьеров для транзакций исходя из программируемой идентичности репутационной активности пользователей блокчейн-сетей и надежности проведения транзакций между ее участниками вне зависимости от места их нахождения и идентификационных данных в открытом доступе.

Важно отметить, что блокчейн технологии, помимо своих явных достоинств, формируют и иного рода последствия, связанные, к примеру, со стоимостью разработки соответствующих блокчейн-платформ, стоимостью их последующего обслуживания по мере масштабируемости обслуживаемых ей процессов и т.п. В этой связи, учитывая, что рассматриваемые технологии, помимо своих явных положительных экстерналий, генерируют и определенного рода риски и ограничения их широкого применения, целесообразно использовать при проведении оценок и выдвижении постулатов теоретического порядка инструменты диалектического анализа к исследованию поставленного вопроса. Это, на наш взгляд, будет способствовать всестороннему пониманию и изучению исследуемых технологий, что минимизирует риски неоднозначной интерпретации получаемых выводов.

В соответствии с данным подходом необходимо однозначно осознавать, что разворачивание подобных блокчейн-систем в хозяйственной среде национальной экономики требует решения целого ряда технических задач. К ним можно отнести: разработку порядка распределения затрат на разворачивание и поддержание блокчейн систем между ее участниками (заинтересованными сторонами); разработку регламента и определения возможных границ обмена данными между участниками платформы; возможность корректировки базы данных в случае обнаружения ошибочной записи о транзакции, соответствие процессов обработки данных на основе блокчейн систем требованиям FINRA [10] в части соблюдения, к примеру, минимальных сроков фиксации записей о реализованных транзакциях, требуемого типа записей и др. Кроме того важнейшим вопросом в череде поставленных являются вычислительные и технологические ресурсы и их потенциал для решения поставленных задач, касающихся создания блокчейнрегистров и их разворачивания в финансовых и иных учреждениях. Учитывая, что реестр блоков в блокчейнсистемах постоянно будет расти и, по всей видимости, храниться на нескольких узлах подобно рода вопрос представляется весьма актуальным в контексте предмета настоящего исследования. Однако, в соответствии с законом Мура, риск нехватки или повышенной загрузки технологических мощностей не велик, ввиду того, что со 
временем процессоры становятся быстрее и дешевле, что позволяет, в свою очередь, по более низкой стоимости обеспечить процесс фиксации и извлечения записей из блокчейн-платформ.

Существуют и другие риски, подробно представленные и проанализированные, к примеру, в исследовании Крылова Г.О., Селезнёва В.М. [11, 12]. К ним необходимо отнести риски, вызванные «возможным отмыванием преступных доходов в силу планетарной структуры распределенных реестров; анонимности и трансграничности блокчейн-транзакций, потенциальных атак типа $51 \%$ др. Эти риски являются главным препятствием внедрения блокчейн технологий в кредитно-финансовой сфере» $[11,12]$. Более того, в соответствии с рекомендациями группы разработки финансовых мер борьбы с отмыванием денег (ФАТФ), являющимися общепризнанными международными стандартами, данного рода риски весьма значимы, ввиду чего Рекомендация 15 провайдерам услуг виртуальных активов обращает внимание на необходимость оценивать риски, которые могут возникнуть «в связи с:

- разработкой новых продуктов и новой деловой практики, включая новые механизмы поставки;

- использованием новых или разрабатываемых технологий как для новых, так и для уже существующих продуктов» [13]».

В концентрированном формате факторы, ограничивающие перспективы широкого разворачивания в системе операционных и хозяйственных процессов национальной экономики блокчейн технологий, представлен ниже:

1. В силу технологических решений блокчейн сети при их значительном масштабировании могут работать весьма медленно ввиду того, что для достижения консенсуса в отношении какой-либо операции требуются затраты времени (генерация новых блоков сети требует дополнительных затрат технологических и иных ресурсов на хранение и обработку данных). [14].

2. Высокая стоимость разработки соответствующих блокчейн-платформ, а также стоимость их последующего обслуживания по мере масштабируемости обслуживаемых ей процессов и т.п.

3. Децентрализованный механизм консенсуса требует использования значительной инфраструктуры и эксплуатационных расходов в области содержания сетей связи, вычислений и хранения данных.

4. Использование блокчейн технологий в финансовом секторе экономики потребует согласования, а возможно и разработки новых процедур проверки, синхронизированных и соответствующих требованиям FINRA.
5. Существенным ограничением использования блокчейн технологий в глобальной системе финансовых транзакций может быть обусловлено ввиду рассогласованности юрисдикционного поля, регламентирующего использование данных технологий в различных странах, включая и процедуры проверки активов перед совершением сделки.

6. Внедрение блокчейн технологий в финансовую среду нарушит порядок ее функционирования и развития ввиду того, что финансовые транзакции смогут генерироваться децентрализованным способом, при этом не нарушая принципы проверки, хранения и защиты данных.

7. Тотальное разворачивание блокчейн технологий в финансовой среде может привести к неизвестным последствиям, ввиду недостаточного опыта их применения на практике.

8. Глобальное разворачивание блокчейн-сетей, «ломающих» официальные границы между государственными юрисдикциями в процессе реализации финансовых транзакций затруднительно ввиду дифференциации нормативно-правовых инструментов регулирования финансовых рынков в различных странах.

9. Блокчейн технологии содержат ряд неопределенностей в области апробации финансовых операций (тотальное разворачивание блокчейн технологий в финансовой среде может привести к неизвестным последствиям, ввиду недостаточного опыта их применения на практике).

10.Блокчейн платформы могут не соответствовать установленным требованиям финансовых транзакций (по скорости обработки данных, КYС, нормативному регулированию в различных странах и др.);

11. Финансовые учреждения весьма скептически относятся к данной технологической инновации, что может ограничить диффузию блокчейн технологий в финансовой системе национального и глобального уровня.

12. Планируемые экономические эффекты от использования в финансовой деятельности блокчейн платформ трудно точно оценить ввиду того, что структура и содержание издержек не сопоставимы с расходами, вызванными в рамках традиционных форм реализации транзакций.

13. Учитывая, что сформировавшаяся финансовая система состоит из множества связанных между собой систем и платформ, замена одной из них блокчейн платформой, скорее всего не позволит ей синхронизироваться с иными системами/подсистемами.

14. Весьма актуальной и значимой проблемой является поиск решений в вопросе сохранения безопасности использования блокчейн-сетей. 
15. Опасения регуляторов по поводу широкого применения блокчейн технологий вызваны целым рядом причин, главными из которых являются децентрализованный характер финансовых транзакций с возможностью их обезличивания, что генерирует риски безконтрольного обращения финансовых ресурсов.

16. Существуют риски криминального использования блокчейн-технологий для несанкционированного и конфиденциального проведения сделок. Финансовые транзакции, основанные на применении цифровых денег (криптовалюты) являются во многом не подконтрольными центральным регуляторам.

17. Национальные экономики абсолютного большинства стран так и не выработали систему нормативно-правовых требований к регулированию процесса использования блокчейн-систем в финансовой и хозяйственной деятельности экономических агентов.

18. Одним из важнейших аргументов, который также может приостановить процессы блокчейнизации финансовой среды является конфиденциальность данных.

19. Учитывая, что блокчейн-системы построены по принципу децентрализованного управления, технической сложностью может стать проблема устранения ошибок, в случае их появления и обнаружения в сети.

20. Пользователи - участники блокчейн-систем имеют возможность оппортунистически фальсифицировать свои идентификационные данные, что формирует риски получения не актуальной (не в полной мере прозрачной) информации о них.

21. Пользователи - участники блокчейн-систем имеют возможность быть псевдонимами.

22. Некоторые данные, вводимые участниками блокчейн-систем, могут быть зашифрованы.

23. Участники блокчейн-систем имеют возможность раскрытия информации о себе на коммерческой основе, что повышает расходы других участников (финансовых организаций), заинтересованных в поиске и сборе информации о них (контрагентах).

24. Блокчейн-системы генерируют риски фрагментации и дублирования данных, в случае утери пользователем закрытого ключа, что формирует необходимость создания нового дублирующего профиля пользователя.

25. Использование «умных» контрактов в блокчейнсистемах требует повышенного уровня затрат на их разработку относительно традиционных форм договоров.

26. В случае, если технологически блокчейн-система использует принципы высокого уровня конфиденциальности, то есть, по сути, ее пользователи являются псевдонимами, расходы на контроль в сфере совершаемых транзакций могут повыситься.

27. Децентрализованный принцип функционирования блокчейн-систем предполагает подключение к ней узлов и данных различных заинтересованных организаций. Однако, учитывая, что данные организации могут выступать в роли конкурентов по отношению друг к другу, существует весьма высокая вероятность того, что они не захотят делиться и выкладывать в свободное обращение какими-то информационные данные. В этом случае можно говорить о некоем препятствии и ограничении перспектив развития блокчейн технологий в сформировавшейся экосреде.

28. Операционные издержки на обеспечение требований KYC и AML могут сместиться с финансовых учреждений на государственные регуляторы. Сформировавшиеся алгоритмы и нормы KYC, AML могут не соблюдаться в рамках блокчейн-систем. Это, по всей видимости, потребует разработки новых правил организации финансовой безопасности в рамках использования блокчейн технологий.

29. Цифровые деньги формируют условия снижения уровня использования традиционных денег. Следовательно, их использование и активное проникновение в систему хозяйственных операций отразиться на развитии финансовой системы национальной экономики, трансформируя и угрожая устойчивости ее фундаментальных основ. Это связано, в первую очередь, с радикальным изменением формы и способов проведения транзакций.

\section{Выводы}

В целом, несмотря на весьма широкий представленный перечень факторов, выступающих на сегодняшний день в роли ограничителей активной диффузии блокчейн технологий в рамках национальной экономической системы, перспективы их интеграции в хозяйственные процессы многими теоретиками и практиками оцениваются как крайне высокие. Подтверждением этому выступают, в частности, данные, представленные ПАО «Ростех» [15]. В соответствии с ними скорость распространения изучаемых технологий оценивается в формате экспоненциального тренда, что, несомненно, связано с представленными положительными экстерналиями, генерирующимися в рамках проникновения блокчейн технологий в хозяйственную среду.

Кроме того, важно отметить, что в последние годы национальные регуляторы многих стран весьма активно прорабатывают вопросы создания национальных цифровых денег. Наблюдаемая в последние годы активность, несомненно, может служить триггером к активи- 
зации и наращиванию исследований, направленных на разработку методических подходов к оценке влияния технологий распределенного хранения данных на параметры развития экономических систем.

\section{Зак^ючение}

Цифровизация социоэкономической среды существенным образом трансформирует традиционные сферы хозяйственной деятельности. На смену аналоговому телевидению пришло цифровое; фиатные платежи заменяются электронными; обмен данных и построенные на их основе управленческие модели перешел в систему электронного документооборота и т.п. Блокчейн технологии также могут существенным образом изменить устоявшиеся процессы и бизнес-модели хозяйствующих субъектов, а также финансовую сферу, продолжив раз- вивать парадигму FinTech.

Представленные аргументы, раскрывающие перспективы развития национальных экономических систем в условиях интеграции в систему хозяйственных процессов блокчейн технологий, свидетельствуют о необходимости разработки методов и алгоритмов формализованной оценки их влияния на ключевые параметры социально-экономической динамики. При этом конечно же подобного рода разработки не могут быть эффективно реализованы без системного понимания главных и сопутствующих эффектов. В связи с чем их группировка является важнейшей методической задачей в пространстве поиска решений, направленных, в том числе, на построение специальных моделей, оценивающих влияние диффузии блокчейн технологий на национальную экономику.

\section{ЛИТЕРАТУРА}

1. de Meijer, C. R. W. (2016). Blockchain and the securities industry: Towards a new ecosystem. Journal of Securities Operations \& Custody, 8(4), 322-329.

2. Marc Andreessen. Why Bitcoin Matters. // The New York Times [сайт]. - January 21, 2014. - URL: https://dealbook.nytimes.com/2014/01/21/why-bitcoin-matters/ (дата обращения 20.05.2020).

3. Pieters G., Vivanco S. Financial regulations and price inconsistencies across Bitcoin markets // Information Economics and Policy- 2017.- Vol. 39. - pp. 1-14.

4. Safiullin M.R., Elshin L.A. Role of higher school in the formation of the fourth industrial revolution in the russian federation. International Journal of Civil Engineering and Technology. 2019. T. 10. № 2. C. 1669-1676.

5. Доклад для общественных консультаций «Цифровой рубль». Банк России. [Электронный ресурс]. - Режим доступа: https://buhguru.com/wp-content/ uploads/2020/10/cb-cifrovoj-rubl-doklad-2020.pdf

6. Сафиуллин М.Р. Абдукаева А.А., Ельшин Л.А. Интегральная многокомпонентная оценка развития рынка блокчейн-технологий в национальной экономике России / Инновации. 2019. № 7 (249). С. 41-49.

7. Tilooby, Al, "The Impact of Blockchain Technology on Financial Transactions." Dissertation, Georgia State University, 2018. https://scholarworks.gsu.edu/bus_ admin_diss/103

8. Yli-Huumo, J., Ko, D., Choi, S., Park, S., \& Smolander, K. (2016). Where Is Current Research on Blockchain Technology?-A Systematic Review. Plos One, 11(10), e0163477-e0163477. doi:10.1371/journal.pone.0163477/

9. Wang A.W. (2018) Crypto Economy. How Blockchain, Cryptocurrency, and Token-Economy Are Disrupting the Financial World. Skyhorse Publishing, 148 P.

10. FINRA. (2017). Distributed Ledger Technology: Implications of Blockchain for the Securities Industry. Retrieved from http://www.finra.org/sites/default/files/ FINRA_Blockchain_Report.pdf.

11. Проблемы безопасности оборота цифровых финансовых активов в криптоэкономике: Монография / Г.0. Крылов, В.М. Селезнев. - М.: Прометей, 2020. $348 \mathrm{c}$.

12. Крылов Г.О., Селезнёв В.М. Состояние и перспективы развития технологии блокчейн в финансовой сфере. Финансы: теория и практика/Finance: Theory and Practice. 2019; 23(6):26-35. https://doi.org/10.26794/2587-5671-2019-23-6-26-35.

13. FATF (2019), Guidance for a Risk-Based Approach to Virtual Assets and Virtual Asset Service Providers, FATF, Рагіs [Электронный ресурс]. - Режим доступа: шww. fatf-gafi.org/publications/fatfrecommendations/documents/Guidance-RBA-virtual-assets.html, свободный (02.03.2021).

14. Towards the Circular Economy Vol. 1: an economic and business rationale for an accelerated transition. The Ellen Macarthur Foundation, 2012.96 p. URL: https:// www.ellenmacarthurfoundation.org/publications/towards-the-circular-economy-vol-1-an-economic-and-business-rationale-for-an-accelerated-transition. (дата обращения 28.05.2020).

15. В России потратят 36 млрд рублей на развитие блокчейна. Что это даст? [Электронный ресурс]. - Режим доступа: https://www.cnews.ru/articles/2020-0419_v_rossii_potratyat_36_mird_rub_na_razvitie, свободный (29.12.2020). 